\title{
The assessment of pain in older people
}

\author{
B Collett, S O'Mahoney, P Schofield, SJ Closs and J Potter, \\ on behalf of the Guideline Development Group*
}

B Collett FRCA, Consultant in Pain Management and Anaesthesia,

University Hospitals of Leicester

S O'Mahoney FRCP, Senior Lecturer and Consultant Physician, Llandough NHS

Trust, Penarth, South Glamorgan

P Schofield PhD, Senior Lecturer, University of Aberdeen

SJ Closs PhD, Chair of Nursing Research,

University of Leeds

J Potter FRCP, 500 Effectiveness and Evaluation Unit, Royal College of Physicians

Concise Guidance to Good Practice Series Editors: Lynne Turner-

Stokes FRCP and Bernard Higgins FRCP
ABSTRACT - Pain is under-recognised and undertreated in older people. It is a subjective, personal experience, only known to the person who suffers. The assessment of pain is particularly challenging in the presence of severe cognitive impairment, communication difficulties or language and cultural barriers. These guidelines set out the key components of assessing pain in older people, together with a variety of practical scales that may be used with different groups, including those with varying levels of cognitive or communication impairment. The purpose is to provide professionals with a set of practical skills to assess pain as the first step towards its effective management. The guidance has implications for all healthcare and social care staff and can be applied in all settings, including the older person's own home, in care homes, and in hospital.

KEY WORDS: assessment, cognitive impairment, older people, pain, pain scales

\section{Background}

Pain is under-recognised and under-treated in older people. National UK statistics have indicated that pain or discomfort was reported by about half of over 65 year olds, and $56 \%$ of men and $65 \%$ of women aged 75 years and over. ${ }^{1}$ Higher prevalence estimates are obtained from samples of institutionalised older people, where $45-83 \%$ of patients report at least one current pain problem. ${ }^{2,3}$

Pain is a subjective, personal experience, only known to the person who suffers. The experience of pain is multidimensional and may be described at several levels:

- Sensory dimension: the intensity, location and character of the pain sensation

- Affective dimension: the emotional component of pain and how pain is perceived

*The Guideline Development Group (GDG) was convened by the British Geriatrics Society and the British Pain Society in conjunction with the Clinical Standards Department of the Royal College of Physicians. For membership of the GDG, please see the end of the paper.
- Impact: the disabling effects of pain on the person's ability to function and participate in society.

The purpose of this guideline is to provide professionals with a set of practical skills to assess pain as the first step towards its effective management. The guidance does not seek to differentiate between acute and persistent pain as the literature relating to pain in older people shows that such a distinction is impractical.

For more detailed guidance and evaluation of the supporting literature, please see the full guideline. ${ }^{4,5}$

\section{The challenge of impaired cognition and communication}

Assessing pain becomes even more challenging in the presence of severe cognitive impairment, communication difficulties or language and cultural barriers. However, even in the presence of severe cognitive and communication impairment, many individuals may have their pain assessed using appropriate observational scales.

Verbal and numerical rating scales best quantify the intensity of pain in older people with no cognitive/communication impairment and can also be used with appropriate assistance in many patients with mild to moderate impairments.

Rating scales should be presented in a format that is accessible for the individual. People who lack verbal and numeracy skills, eg those with cognitive impairment or communication impairment following stroke, may be able to respond to a suitably adapted pictorial rating scale. ${ }^{6.7,8}$ Assistance from a speech and language therapist or psychologist may help to facilitate self-report in the presence of more severe impairment.

Scales should use large clear letters/numbers and be presented under good lighting. Once the most appropriate scale has been chosen to suit the individual person's strengths, staff should continue to use this for sequential assessment in order to observe the response to treatment.

People with very severe cognitive/communication impairment may not be able to self-report pain even with full assistance. Clinicians may need to rely on behavioural responses, but these can be hard to interpret. 
Box 1. Key components of an assessment of pain.

- Direct enquiry about the presence of pain

- including the use of alternative words to describe pain

- Observation for signs of pain

- especially in older people with cognitive/communication impairment

- Description of pain to include:

- sensory dimension

- the nature of the pain (eg sharp, dull, burning etc)

- pain location and radiation (by patients pointing to the pain on themselves or by using a pain map)

- intensity, using a standardised pain assessment scale

- affective dimension

- emotional response to pain (eg fear, anxiety, depression)

- impact: disabling effects of pain at the levels of

- functional activities (eg activities of daily living)

- participation (eg work, social activities, relationships)

- Measurement of pain

- using standardised scales in a format that is accessible to the individual

- Cause of pain

- examination and investigation to establish the cause of pain

Table 1. Observational changes associated with pain.

\begin{tabular}{ll}
\hline Type & Description \\
\hline Autonomic changes & Pallor, sweating, tachypnoea, altered breathing patterns, tachycardia, hypertension \\
Facial expressions & $\begin{array}{l}\text { Grimacing, wincing, frowning, rapid blinking, brow raising, brow lowering, cheek raising, eyelid tightening, } \\
\text { nose wrinkling, lip corner pulling, chin raising, lip puckering }\end{array}$ \\
Body movements & Altered gait, pacing, rocking, hand wringing, repetitive movements, increased tone, guarding, bracing** \\
Verbalisations/vocalisations & Sighing, grunting, groaning, moaning, screaming, calling out, aggressive/offensive speech \\
Interpersonal interactions & Aggression, withdrawal, resisting \\
Changes in activity patterns & Wandering, altered sleep, altered rest patterns \\
Mental status changes & Confusion, crying, distress, irritability
\end{tabular}

*Guarding = 'abnormal stiff, rigid, or interrupted movement while changing position'.

**Bacing $=$ a stationary position in which a fully extended limb maintains and supports an abnormal weight distribution for at least three seconds.

\section{Assessment}

The key components of an assessment for anyone suffering from pain are shown in Box 1. It is particularly important to use observations for signs of pain in older people with cognitive or communication impairment (Table 1).

\section{Types of scale used to assess pain}

A list of existing scales and the evidence for their use is available in the full guideline. ${ }^{4,5}$ Table 2 provides examples of scales which are suitable for clinical use in different categories of patient. It is not yet clear which observational scale is the most suitable for widespread use with people who have severe cognitive impairment, so an example has been selected on the basis of simplicity and availability. Ongoing validation studies are likely to inform the selection of scales for use in the near future.

\section{Implications and implementation}

The guidance has implications for all healthcare and social care staff and can be applied in all settings, including the older person's own home, in care homes, and in hospital.

There is no significant funding implication for implementation, but rather a requirement that all healthcare professionals think about the possibility of pain in all contacts with older people, enquire about it routinely, be aware of behaviours that indicate underlying pain and have pathways for management.

The proper evaluation of pain in older people does require staff training and the additional time required to undertake a proper evaluation will inevitably impact on staff time in already over-pressed services. However, if pain is sought out, addressed and relieved, the lot of older people would be greatly enhanced. Moreover, relief from the disabling effects of pain may potentially save staff time in other areas such as the provision of 
Table 2. Types of scale for assessing pain.

\begin{tabular}{|c|c|c|}
\hline Type of pain assessment & $\begin{array}{l}\text { Practical suggestions } \\
\text { for scale selection }\end{array}$ & Comments and references \\
\hline \multicolumn{3}{|l|}{ Self-report } \\
\hline \multirow{5}{*}{$\begin{array}{l}\text { Older people with no significant } \\
\text { cognitive/communication impairment } \\
\text { and } \\
\text { Older people with mild to moderate } \\
\text { cognitive/communication impairment }\end{array}$} & \multirow[t]{4}{*}{ Numeric graphic rating scale } & High validity and reliability in older people ${ }^{9-11}$ \\
\hline & & Can be used in mild/moderate cognitive impairment ${ }^{9,12}$ \\
\hline & & Vertical as opposed to horizontal orientation may help \\
\hline & & $\begin{array}{l}\text { to avoid misinterpretation in the presence of visuo-spatial } \\
\text { neglect eg in patients with stroke }\end{array}$ \\
\hline & $\begin{array}{l}\text { Verbal rating scale or } \\
\text { numerical rating scale }(0-10)\end{array}$ & High validity and reliability in older people $\mathrm{e}^{9-11}$ \\
\hline \multirow{3}{*}{$\begin{array}{l}\text { Older people with moderate to severe } \\
\text { cognitive/communication impairment }\end{array}$} & Pain Thermometer 6 & Easy to use \\
\hline & & Validity has not been fully evaluated ${ }^{6}$ \\
\hline & Coloured Visual Analogue Scale ${ }^{7}$ & $\begin{array}{l}\text { Well understood in early and mid-stage Alzheimer's } \\
\text { disease }^{8}\end{array}$ \\
\hline \multicolumn{3}{|l|}{ Observational pain assessment } \\
\hline \multirow{2}{*}{$\begin{array}{l}\text { Older people with severe cognitive/ } \\
\text { communication impairment } \\
\text { (no single recommendation currently } \\
\text { possible) }\end{array}$} & \multirow[t]{2}{*}{ ABBEY Pain Scale ${ }^{13,14}$} & Short and easy to apply scale ${ }^{13}$ \\
\hline & & Requires more detailed evaluation \\
\hline \multicolumn{3}{|l|}{ Multidimensional assessment } \\
\hline $\begin{array}{l}\text { Older people with minimal cognitive } \\
\text { impairment }\end{array}$ & Brief Pain Inventory ${ }^{15,16}$ & $\begin{array}{l}\text { 15-item scale assessing: severity, impact on daily living, } \\
\text { impact on mood and enjoyment of life }\end{array}$ \\
\hline
\end{tabular}

support for basic self-care activities etc. These basic guidelines should be a routine part of the training and care provision of all healthcare professionals.

\section{Methodology}

The guidance has been developed in accordance with the requirements for concise guidelines as detailed at www.rcplondon. ac.uk/college/ceeu/conciseGuidelineDevelopmentNotes.pdf A fuller version of this guidance is published in booklet form. ${ }^{17}$

\section{Acknowledgements}

The Guideline Development Group (GDG) would like to thank and acknowledge the support received from Jo Gough for her administrative help in organising the activities of the GDG and in assisting with the drafting of the guidance. The GDG are also grateful to the British Pain Society and the British Geriatrics Society for the provision of facilities for meetings, and to the peer reviewers who took the time to provide valuable and considered feedback

\section{Members of the Guideline Development Group}

Professor SJ Closs (Nursing), Chair of Nursing Research, University of Leeds; Dr B Collett (Pain medicine), Consultant in Pain Management and Anaesthesia, University Hospitals of Leicester; Dr J Giffin (Patient representative); Mrs J Gough (Administrative support), British Geriatrics Society, London; Dr D Harari (Geriatric medicine) Consultant Physician/Senior Lecturer, St Thomas's Hospital, London; Mr L Jones (Physiotherapy), Senior Lecturer, Kingston University and University of London; Dr S O’Mahony (Geriatric medicine), Senior Lecturer/Consultant Physician, Llandough NHS Trust, Penarth, South Glamorgan; Dr J Potter (Clinical Effectiveness and Evaluation Unit, Royal College of Physicians) Consultant Physician, Kent and Canterbury Hospital, Canterbury; Dr P Schofield (Nursing) Senior Lecturer, University of Aberdeen, Aberdeen. Consultation with Dr A Williams (Clinical psychology), Reader in Clinical Health Psychology, University of London.

\section{References}

1 National Statistics Online. Self-reported health problems: by gender and age, 1996-97: social trends dataset. www.statistics.gov.uk/ StatBase $/$ xsdataset.asp? More $=Y \& v \operatorname{lnk}=670 \& A l l=Y \& B 2 . x=86 \& B 2 . y=13$ (accessed 22 May 2007).

2 Helme RD, Gibson SJ. The epidemiology of pain in elderly people. Clin Geriatr Med 2001;17:417-31.

3 Ferrell BA, Ferrell BR, Osterweil D. Pain in the nursing home. J Am Geriatr Soc 1990;38;409-14.

4 British Geriatrics Society, 2007. www.bgs.org.uk/Publications/ Clinical\%20Guidelines/clinical_guidelines_index.htm

5 British Pain Society, 2007. www.britishpainsociety.org

6 AGS Panel on Persistent Pain in Older Persons. The management of persistent pain in older persons. J Am Geriatr Soc 2002;50:S205-24.

7 Scherder EJA, Bouma A. Visual analogue scales for pain assessment in Alzheimer's disease. Gerontology 2000;46:47-53. 


\section{Summary of the guidelines}

\section{Pain awareness}

All healthcare professionals should be alert to the possibility of pain in older people, and to the fact that older people are often reluctant to acknowledge and report pain.

\section{Pain enquiry}

Any health assessment should include enquiry about pain, using a range of alternative descriptors (eg sore, hurting, aching).

\section{Pain description}

Where pain is present, a detailed clinical assessment of the multidimensional aspects of pain should be undertaken including:

- sensory dimension: the nature, location and intensity of pain

- affective dimension: the emotional component and response to pain

- impact: on functioning at the level of activities and participation.

\subsection{Pain location}

An attempt to locate pain should be made by:

- asking the patient to point to the area on themselves

- the use of pain maps to define the location and the extent of pain.

\subsection{Pain intensity}

Pain assessment should routinely include the use of a standardised intensity rating scale, preferably a simple verbal descriptor scale or a numeric rating scale, if the person is able to use these.

\section{Communication}

Every effort should be made to facilitate communication particularly with those people with sensory impairments (use of hearing aids, glasses etc).

Self-report assessment scales should be offered in an accessible format to suit the strengths of the individual.

\section{Assessment in people with impaired cognition/communication}

People with moderate to severe communication problems should be offered additional assistance with self-report through the use of suitably adapted scales and facilitation by skilled professionals.

In people with very severe impairment, and in situations where procedures might cause pain, an observational assessment of pain behaviour is additionally required (see Table 1).

Pain behaviours differ between individuals, so assessment should include insights from familiar carers and family members to interpret the meaning of their behaviours.

\section{Cause of pain}

Careful physical examination should be undertaken to identify any treatable causes. However, staff should be aware that pain can exist even if physical examination is normal.

\section{Re-evaluation}

Once a suitable scale has been identified, serial assessment should be undertaken using the same instrument to evaluate the effects of treatment. 
8 Hadjistavropoulos T, Herr K, Turk D et al. An interdisciplinary expert consensus statement on assessment of pain in older persons. Clin J Pain 2007;23:S1-43

9 Chibnall JT, Tait RC. Pain assessment in cognitively impaired and unimpaired older adults: a comparison of four scales. Pain 2001;92: 173-86.

10 Herr KA, Spratt K, Mobily PR, Richardson G. Pain intensity assessment in older adults. Clin J Pain 2004;20:207-19.

11 Kaasalainen S, Crook J. An exploration of seniors' ability to report pain. Clin Nurs Res 2004;13:199-215.

12 Stolee P, Hillier L, Esbaugh J et al. Instruments for the assessment of pain in older persons with cognitive impairment. J Am Geriatr Soc 2005;53:319-26.

13 Abbey J, Piller N, De Bellis A et al. The Abbey pain scale: a 1-minute numerical indicator for people with end-stage dementia. Int J Palliat Nurs 2004;10:6-13.

14 Abbey J, De Bellis A, Piller N et al. Abbey pain scale. In: The Royal Australian College of General Practitioners - 'Silver Book' National Taskforce. Medical care of older persons in residential aged care facilities. www.racgp.org.au/silverbookonline/4-6.asp

15 Keller S, Bann CM, Dodd SL et al. Validity of the brief pain inventory for use in documenting the outcomes of patients with noncancer pain. Clin J Pain 2004;20:309-18.

16 Pain Research Group, University of Wisconsin-Madison. Brief pain inventory. In: The Royal Australian College of General Practitioners 'Silver Book' National Taskforce. Medical care of older persons in residential aged care facilities.

www.racgp.org.au/silverbookonline/4-7.asp

17 Royal College of Physicians, British Geriatrics Society and British Pain Society. The assessment of pain in older people: national guidelines. Concise guidance to good practice series, No 8. London: RCP, 2007. www.rcplondon.ac.uk/pubs/brochure.aspx?.e=233

\section{New Title}

\section{The assessment of pain in older people: national guidelines}

Concise guidance to good practice series, No 8.

The guideline, with its accompanying laiminated algorithm, comprises an accessible tool for assessing pain in older people. The guidance will be of use to all healthcare professionals working with older people including those in hospital, in the community and in care homes.

ISBN 978-1-86016-318-0

Price $£ 7.00$ (UK) and $£ 9.00$ (overseas)

For further information, please contact the Publications

Department, Royal College of Physicians. 